\title{
Article \\ Effects of Shading on the Internode Critical for Soybean (Glycine Max) Lodging
}

\author{
Fuxin Shan ${ }^{1}{ }^{1}$, Kexin Sun ${ }^{1}$, Shengdan Gong ${ }^{1}$, Chang Wang ${ }^{1}\left(\mathbb{D}\right.$, Chunmei Ma ${ }^{1}$, Rui Zhang ${ }^{2, *}$ and Chao Yan ${ }^{1, *}$ \\ 1 College of Agriculture, Northeast Agricultural University, Harbin 150030, China; \\ sfx18846424314@163.com (F.S.); skx157422192@163.com (K.S.); gongshengdan2711@163.com (S.G.); \\ 18249555621@163.com (C.W.); chunmm518@163.com (C.M.) \\ 2 College of Agronomy and Biotechnology, Yunnan Agricultural University, Kunming 650201, China \\ * Correspondence: zhang134rui@163.com (R.Z.); yanchao504@126.com (C.Y.)
}

check for updates

Citation: Shan, F.; Sun, K.; Gong, S. Wang, C.; Ma, C.; Zhang, R.; Yan, C. Effects of Shading on the Internode Critical for Soybean (Glycine Max) Lodging. Agronomy 2022, 12, 492. https://doi.org/10.3390/ agronomy12020492

Academic Editor: Sara Di Lonardo

Received: 10 January 2022

Accepted: 13 February 2022

Published: 16 February 2022

Publisher's Note: MDPI stays neutral with regard to jurisdictional claims in published maps and institutional affiliations.

Copyright: (C) 2022 by the authors. Licensee MDPI, Basel, Switzerland. This article is an open access article distributed under the terms and conditions of the Creative Commons Attribution (CC BY) license (https:// creativecommons.org/licenses/by/ $4.0 /)$.

\begin{abstract}
Increasing planting density is among the most effective ways to increase soybean yield, but high planting density increases lodging risks in soybean plants. To examine the effects of shading on soybean plant lodging, the tall cultivar Heinong 48 (HN48) and dwarf cultivar Henong 60 (HN60), two soybean cultivars with large plant height differences (approximately $40 \mathrm{~cm}$ ), were selected, and their internode lengths were measured under different planting densities in 2019 to determine the key internode influencing lodging. In 2020, we treated soybean plants with different shading treatments to examine the morphology, anatomical structure and stem fiber composition of the fifth internode, changes in the $\mathrm{GA}_{3}$ (gibberellic acid) content, and relative expression of $\mathrm{GA}_{3}$-related enzyme genes in the stem under different shading conditions. The results showed that as the planting density increased, the lengths of the internodes changed significantly, starting from the fifth internode. Under different shading conditions, the length of the fifth internode increased for both cultivars, but the diameter and the diameter-to-length ratio decreased; the area of the xylem decreased, and the pith cells stretched more longitudinally and were more orderly; the lignin, cellulose, and hemicellulose contents decreased; the $\mathrm{GA}_{3}$ content in the stem increased, and the expression levels of GmGA3ox6, GmGA20ox1-D, and GmGA2ox4 enzyme genes were all upregulated; and the change in PSN treatment was more significant than other treatments. Therefore, the fifth internode was the key internode that affected lodging in soybean plants, shading could increase the $\mathrm{GA}_{3}$ content significantly in soybean stems, and the increase in $\mathrm{GA}_{3}$ content was positively correlated with the shaded area. This study provides a new direction for future research on lodging resistance in densely planted or intercropped soybean plants.
\end{abstract}

Keywords: planting density; gibberellic acid; lodging; anatomical structure

\section{Introduction}

Light plays an important role in regulating plant growth and development. Under high planting densities, the crop canopy structure is negatively affected, while the competition for light resources within the plant population intensifies, leading to a high tendency toward lodging. The lodging of soybean plants hinders the transportation of water and the distribution of nutrients as well as the transport of photosynthetic products from leaves to pods, thereby severely affecting soybean yields [1,2]

Plants are often grown under varying degrees of shade [3]. In [4], shading promoted rapid elongation of stems and petioles and reduced branches while significantly decreasing the photosynthetic rate, harvest index, and stem mechanical strength. The mechanical strength of plant stems depends on the contents of cell wall components, such as cellulose and lignin [5]. Liu et al. [6] showed that soybean-corn intercropping significantly reduces the cellulose accumulation and stem tension of soybean stems. The xylem area, lignin content, and activities of phenylalanine ammonia lyase, 4-coumarate:coenzyme A ligase, 
cinnamyl alcohol dehydrogenase, and peroxidase of shade-tolerant soybean cultivars were higher than those of shade-intolerant cultivars, and shade-tolerant cultivars had thicker xylem, more vascular tissues and vessels, smaller pith areas, and thicker stems [7]. Hussain et al. [8] argued that shading reduces the amount of lignin deposited in the cells of vascular bundles and sclerenchyma, rendering the stems slender and more fragile. Cheng et al. [9] showed that when soybeans were intercropped, decreasing their planting density could increase the activity of lignin-related enzymes and the accumulation of carbohydrates, thereby enhancing the lodging resistance of soybean stems.

Changes in the level of plant hormones are crop active responses to adverse conditions, and they provide physiological bases for plants to use assimilation products better. Under shading, the abscisic acid (ABA) and zeatin (ZT) contents of soybean stems and leaves decrease, and those of indole acetic acid (IAA) and gibberellins (GAs) increase, while the IAA $/ \mathrm{GA}_{1}$ ratio decreases [10-12]. Yuan and Yang [13] found that shading led to an increase in $\mathrm{GA}_{3}$ content in the leaves of the Himalayan lily (Cardiocrinum giganteum). Gawronska et al. [14] revealed that the level of GAs in Pisum sativum seedlings was significantly increased under weak light or dark conditions and that, in particular, the $\mathrm{GA}_{20}$ content was increased 7.6-fold. Three key enzyme genes (i.e., GA20ox, GA3ox, and $G A 20 x$ ) were found to be involved in GA biosynthesis. The negative feedback gene expression regulation of GA20ox and GA3ox and the feedforward gene expression regulation of GA2ox jointly regulate GA levels [15]. Hedden and Phillips [16] concluded that increase in GA content results from an increase in the expression of two GA synthesis genes (GA3ox and GA20ox). Coles et al. [17] found that it is possible to reduce the lodging rate of plants by changing the plant height through lowering GA levels by downregulating GA2ox gene expression.

In agricultural production, dense planting or intercropping soybean crops inevitably leads to shade stress, which affects soybean yield and quality. The photosynthetic parameters, phenotypes, stem mechanical properties, and yield dynamics of soybeans have been extensively studied, while the key internodes that determine the lodging of soybean plants under shading and their fiber composition, anatomical structure, and GA regulation mechanism have not been thoroughly investigated. Therefore, in this study, we selected two soybean cultivars with approximately $40 \mathrm{~cm}$ plant height differences as test materials through different shading treatments that simulated various field shading environments and combined fields to investigate the key internodes that affect soybean lodging under dense planting conditions. We observed the anatomical structure of the stems and analyzed the fiber composition, $\mathrm{GA}_{3}$ content, and the relative expression of the metabolism-related of GA enzyme genes in the stems. This study clarifies that the key internodes that affect soybean lodging are regulated by shading and $\mathrm{GA}_{3}$, and it provides a reference for improving the lodging resistance of densely planted soybean crops.

\section{Materials and Methods}

\subsection{Experimental Design}

2.1.1. Comparison of Soybean Internode Lengths Growing under Different Planting Densities

This experiment was conducted at the Xiangyang experimental practice base of Northeast Agricultural University in Harbin, Heilongjiang Province, China, in 2019. The tall cultivar Heinong 48 (HN48) and the dwarf cultivar Henong 60 (HN60) were selected as test materials and planted at four densities (i.e., 100,000 (D10), 200,000 (D20), 300,000 (D30), and 400,000 (D40) plants per hectare). Normal densities during field production are 300,000 plants per hectare for HN48 and 400,000 plants per hectare for HN60. During planting, soybean plants were planted in two rows on ridges $10 \mathrm{~m}$ in length and $0.65 \mathrm{~m}$ in width (eight ridges per plot) at three seeds per hole to ensure full standing, and the seedlings were thinned at the V3 stage to the set density. For each treatment, four replicates were randomly set in each plot. Standard agronomic practices for soybean production in this area were used, including fertilizers at $150 \mathrm{~kg}$ per hectare of diammonium hydrogen 
phosphate $\left(\mathrm{N}: 18 \%, \mathrm{P}_{2} \mathrm{O}_{5}: 46 \%\right)$ and $75 \mathrm{~kg}$ per hectare of potassium sulfate $\left(\mathrm{K}_{2} \mathrm{O}: 50 \%\right)$, herbicides, and irrigation as needed to minimize drought stress. After the harvest, the length of each internode of the soybean plant sample was measured. The basic soil fertility measurements of the plot were as follows: organic matter, $34.6 \mathrm{~g} / \mathrm{kg}$; available nitrogen, $82.5 \mathrm{mg} / \mathrm{kg}$; available phosphorus, $58.2 \mathrm{mg} / \mathrm{kg}$; and available potassium, $172.2 \mathrm{mg} / \mathrm{kg}$.

\subsubsection{Effects of Shading on Anatomical Structure and Fiber Composition of Soybean Stems}

The experiment was performed in 2020. The experiments were conducted in pots (opening diameter: $33.5 \mathrm{~cm}$; bottom diameter: $24.5 \mathrm{~cm}$; depth: $27.5 \mathrm{~cm}$ ) containing $14 \mathrm{~kg}$ of air-dried black soil collected from a corn field and fertilized with $1.5 \mathrm{~g}$ of diammonium phosphate $\left(18 \%\right.$ nitrogen $\left.(\mathrm{N}), 46 \% \mathrm{P}_{2} \mathrm{O}_{5}\right)$ and $0.75 \mathrm{~g}$ of potassium sulfate $\left(50 \% \mathrm{~K}_{2} \mathrm{O}\right)$. The soil fertility measurements were as follows: organic matter, $31.9 \mathrm{~g} / \mathrm{kg}$; available nitrogen, $63.0 \mathrm{mg} / \mathrm{kg}$; available phosphorus, $75.1 \mathrm{mg} / \mathrm{kg}$; and available potassium, $299.0 \mathrm{mg} / \mathrm{kg}$. Three seedlings with $10 \mathrm{~cm}$ of spacing were retained in each pot.

The tested cultivars were HN48 and HN60, and four treatments were established: natural light (NL), shading of the apical meristem (SAM), covering of all internodes with aluminum foil (CAF), and whole-plant shading with plastic shading nets (PSN). For the SAM treatment, the soybean apical meristem was covered by a plastic lid to protect it from direct sunlight, but the lid did not affect the light on other parts of the plant. For the CAF treatments, the entire internode was wrapped with aluminum foil starting from the development of the first internode. For the PSN treatments, the whole soybean plant was shaded from light by a shading net, starting from the development of the first internode. For the detailed preparation method of the test materials, refer to Zhang's method [18]. Once the first pair of true leaves expanded, shading treatments were started, and when the seventh trifoliolate leaf emerged, the morphological indicators, anatomical structure, and fiber composition of the fifth internode were measured. For each treatment, 18 plants were tested.

\subsubsection{Effects of Shading on GAs in Soybean Stem and the Relative Expression of} GA-Related Enzyme Genes

The experiment was conducted in 2020 using pot experiments, in which the two soybean cultivars were subjected to short- and long-term shading treatments, as described in Section 2.1.2. Short-term shading treatment refers to different shading treatments after the fifth internode of the soybean plant emerged, and the fifth internode was sampled on the first, second, third, and fifth days after the shading treatment as well as the day when the seventh trifoliolate leaf expanded. In addition, the long-term shading treatment continued with different shading treatments from when the first pair of true leaves expanded until the seventh trifoliolate leaf emerged, and the soybean plants were sampled at the fifth internode. The samples were frozen in liquid nitrogen and stored at $-80^{\circ} \mathrm{C}$ for subsequent analyses. At the end of the experiment, the sampled internodes were subjected to analysis of $\mathrm{GA}_{3}$ content and real-time quantitative polymerase chain reaction assay.

\subsection{Measurements and Analyses}

Morphological index measurement: The internode length and diameter were measured with rulers and Vernier calipers, respectively.

Observation of anatomical structure: When the seventh trifoliolate leaf emerged, the middle of the fifth internode of the soybean plant under each of the treatments was sampled, from which horizontal and longitudinal sections were prepared with a blade and then subjected to ethanol dehydration, tert-butanol solution substitution, drying with an ES-2030 freeze dryer, application of conductive resin, coating with an E-1010 ion sputtering coating device (Hitachi, Ltd., Tokyo, Japan), and microscopy with an S-3400 scanning electron microscope(Hitachi, Ltd., Tokyo, Japan) [19].

Determination of stem fiber composition: For each treatment, the middle of the fifth internode of four soybean plants with uniform growth was sampled, wrapped in aluminum 
foil, quickly frozen in liquid nitrogen, and then transferred to a $-80^{\circ} \mathrm{C}$ freezer for storage. An enzyme-linked immunosorbent assay (ELISA) was performed, in which $0.1 \mathrm{~g}$ of fresh soybean stem sample was used to analyze the lignin, cellulose, hemicellulose, starch, sucrose, and soluble sugar contents using plates (Shanghai Enzyme Linked Biotechnology Co., Ltd., Shanghai, China), with eight replications for each sample.

Soybean stem $\mathrm{GA}_{3}$ content determination: An amount of $0.1 \mathrm{~g}$ of the freeze-dried sample was accurately weighed and ground in aqueous phosphate-buffered saline $(\mathrm{pH}=7.4)$ solution and then centrifuged at $4000 \mathrm{r} / \mathrm{min}$ for $15 \mathrm{~min}$. The supernatant was added to the wells of the ELISA plate. The optical density (OD) of each well was measured at 450 $\mathrm{nm}$ after enzyme addition, incubation, washing, coloring, and termination. The OD values were inserted into the standard curve, and the $\mathrm{GA}_{3}$ concentrations were calculated. For each treatment, eight assays were performed.

Determination of the relative expression levels of genes related to GA metabolism: In this experiment, GmGA20ox1-D, GmGA3ox6, and GmGA2ox4 genes encoding key enzymes for GA metabolism were selected for differential expression analysis using the soybean $18 \mathrm{~S}$ gene as the internal reference gene (actin). The NCBI tool Primer-BLAST was used for primer design and verification. The primer sequences are shown in Table 1.

Table 1. Primer sequences of GA-related genes.

\begin{tabular}{|c|c|}
\hline Target Name & Primer Sequences \\
\hline GmGA3ox6-F & 5'-AACTTCTACCCTCGTTGTCCTGA-3' \\
\hline GmGA3ox6-R & 5'-CACTGAGTATCTTTCCCTTGCG-3' \\
\hline GmGA20ox1-D-F & 5'-CTCAAAACACATCCGCAGAAAA-3' \\
\hline GmGA20ox1-D—R & 5'-GGAGGGTATGTTGGACTGGT-3' \\
\hline GmGA2ox4-F & 5'-AACAGTTTGCTACAACAGTTTCGAG-3' \\
\hline GmGA2ox4-R & 5'-CATGAGACCGTGAATCCCAAA-3' \\
\hline Actin-F & 5'-CCATAAACGATGCCGACCAG-3' \\
\hline Actin-R & 5'-AGCCTTGCGACCATACTCCC-3' \\
\hline
\end{tabular}

Note: The selected target genes are the genes detected in soybean stems.

\subsection{Statistical Analysis}

SPSS 17.0 (SPSS, Chicago, IL, USA) was used to analyze the data, and all the data were tested for normality prior to one-way analysis of variance (ANOVA). Duncan's multiple range test was used with a significance level of $p<0.05$. Origin software, version 9.0, (OriginLab, Northampton, MA, USA) was used to generate the figures. Microsoft Publisher software (Microsoft, Redmond, WA, USA) was used to synthesize the selected images.

\section{Results}

\subsection{Comparison of Soybean Internode Length at Harvest under Different Planting Densities}

Table 2 shows a comparison of soybean internode lengths from plants at harvest under different planting densities. The lengths of the upper and middle internodes clearly contributed the most to plant height, while those of the lower internodes contributed little. Under different planting densities, the increase in planting density had little effect on the lengths of the first to fourth internodes. Starting from the fifth internode, the changes in the length of each internode under different planting densities showed a similar pattern (D40 > D30 > D20 > D10), with significant differences between the treatments. Both cultivars showed the same pattern. 
Table 2. Internode length under different planting densities (cm).

\begin{tabular}{|c|c|c|c|c|c|}
\hline Cultivar & $\begin{array}{c}\text { Internode } \\
\text { Position }\end{array}$ & D10 & D20 & D30 & D40 \\
\hline \multirow[t]{13}{*}{ HN48 } & 1 & $3.80 \pm 0.06 \mathrm{a}$ & $3.83 \pm 0.04 \mathrm{a}$ & $3.97 \pm 0.08 \mathrm{a}$ & $4.03 \pm 0.11 \mathrm{a}$ \\
\hline & 2 & $2.40 \pm 0.05 b$ & $2.42 \pm 0.05 b$ & $2.53 \pm 0.02 \mathrm{ab}$ & $2.57 \pm 0.04 \mathrm{a}$ \\
\hline & 3 & $2.07 \pm 0.03 b$ & $2.10 \pm 0.04 b$ & $2.52 \pm 0.06 \mathrm{a}$ & $2.53 \pm 0.04 \mathrm{a}$ \\
\hline & 4 & $2.52 \pm 0.09 c$ & $2.57 \pm 0.06 c$ & $3.62 \pm 0.05 b$ & $4.00 \pm 0.05 a$ \\
\hline & 5 & $3.07 \pm 0.49 \mathrm{~d}$ & $3.47 \pm 0.05 c$ & $4.40 \pm 0.06 \mathrm{~b}$ & $5.17 \pm 0.08 \mathrm{a}$ \\
\hline & 6 & $2.92 \pm 0.05 \mathrm{~d}$ & $3.53 \pm 0.02 c$ & $3.87 \pm 0.04 b$ & $4.43 \pm 0.04 \mathrm{a}$ \\
\hline & 7 & $3.30 \pm 0.03 \mathrm{~d}$ & $3.85 \pm 0.07 c$ & $4.58 \pm 0.07 b$ & $5.10 \pm 0.08 \mathrm{a}$ \\
\hline & 8 & $4.17 \pm 0.06 \mathrm{~d}$ & $4.65 \pm 0.05 c$ & $5.35 \pm 0.11 b$ & $6.35 \pm 0.06 \mathrm{a}$ \\
\hline & 9 & $3.70 \pm 0.06 \mathrm{~d}$ & $5.07 \pm 0.07 c$ & $5.53 \pm 0.03 b$ & $6.18 \pm 0.08 \mathrm{a}$ \\
\hline & 10 & $3.95 \pm 0.03 \mathrm{~d}$ & $5.17 \pm 0.06 c$ & $5.85 \pm 0.08 b$ & $6.17 \pm 0.08 \mathrm{a}$ \\
\hline & 11 & $4.25 \pm 0.08 \mathrm{~d}$ & $4.77 \pm 0.08 c$ & $6.22 \pm 0.05 b$ & $6.43 \pm 0.03 a$ \\
\hline & 12 & $4.43 \pm 0.03 \mathrm{~d}$ & $5.23 \pm 0.09 c$ & $7.05 \pm 0.03 b$ & $7.97 \pm 0.08 \mathrm{a}$ \\
\hline & 13 & $5.13 \pm 0.09 b$ & $7.42 \pm 0.06 \mathrm{a}$ & $7.45 \pm 0.07 \mathrm{a}$ & $7.50 \pm 0.04 \mathrm{a}$ \\
\hline \multirow[t]{13}{*}{ HN60 } & 1 & $2.82 \pm 0.03 \mathrm{a}$ & $2.85 \pm 0.08 \mathrm{a}$ & $2.92 \pm 0.04 \mathrm{a}$ & $2.93 \pm 0.03 a$ \\
\hline & 2 & $1.80 \pm 0.04 \mathrm{a}$ & $1.82 \pm 0.04 \mathrm{a}$ & $1.90 \pm 0.03 \mathrm{a}$ & $1.92 \pm 0.04 \mathrm{a}$ \\
\hline & 3 & $1.47 \pm 0.02 b$ & $1.68 \pm 0.04 \mathrm{a}$ & $1.70 \pm 0.03 \mathrm{a}$ & $1.72 \pm 0.04 \mathrm{a}$ \\
\hline & 4 & $1.58 \pm 0.03 b$ & $1.60 \pm 0.04 b$ & $1.63 \pm 0.03 \mathrm{ab}$ & $1.72 \pm 0.03 \mathrm{a}$ \\
\hline & 5 & $2.05 \pm 0.03 \mathrm{~d}$ & $2.40 \pm 0.04 c$ & $3.23 \pm 0.09 b$ & $3.77 \pm 0.12 \mathrm{a}$ \\
\hline & 6 & $2.02 \pm 0.02 \mathrm{~d}$ & $2.43 \pm 0.06 c$ & $3.17 \pm 0.08 b$ & $3.50 \pm 0.04 \mathrm{a}$ \\
\hline & 7 & $2.07 \pm 0.04 \mathrm{~d}$ & $2.48 \pm 0.04 c$ & $3.17 \pm 0.10 \mathrm{~b}$ & $3.57 \pm 0.03 \mathrm{a}$ \\
\hline & 8 & $2.68 \pm 0.05 \mathrm{~d}$ & $3.73 \pm 0.15 c$ & $4.70 \pm 0.14 b$ & $5.47 \pm 0.07 \mathrm{a}$ \\
\hline & 9 & $3.32 \pm 0.04 \mathrm{~d}$ & $3.78 \pm 0.08 c$ & $4.35 \pm 0.09 \mathrm{~b}$ & $5.53 \pm 0.11 \mathrm{a}$ \\
\hline & 10 & $3.45 \pm 0.02 \mathrm{~d}$ & $4.42 \pm 0.03 c$ & $4.83 \pm 0.08 \mathrm{~b}$ & $5.50 \pm 0.04 \mathrm{a}$ \\
\hline & 11 & $3.08 \pm 0.04 \mathrm{~d}$ & $4.02 \pm 0.05 c$ & $5.15 \pm 0.15 b$ & $6.88 \pm 0.15 a$ \\
\hline & 12 & $3.77 \pm 0.14 \mathrm{~d}$ & $4.53 \pm 0.08 c$ & $6.28 \pm 0.10 b$ & $7.27 \pm 0.08 \mathrm{a}$ \\
\hline & 13 & $3.17 \pm 0.10 b$ & $4.48 \pm 0.09 b$ & $4.58 \pm 0.23 \mathrm{ab}$ & $4.95 \pm 0.10 \mathrm{a}$ \\
\hline
\end{tabular}

Note: D10: 100,000 plants per hectare; D20: 200,000 plants per hectare; D30: 300,000 plants per hectare; D40: 400,000 plants per hectare. The values in the table are the means \pm standard error $(n=5)$. The different letters indicate that the difference between the treatments reached significance at the level of $p<0.05$; the treatments are compared horizontally.

\subsection{Effects of Shading on Morphological Indexes of Soybean Internodes}

Table 3 shows the changes in the internode length, internode diameter, and internodediameter-to-internode-length ratio of the fifth internode under different shading treatments. Shading significantly increased the length of the fifth internode in the order PSN > CAF $>\mathrm{SAM}>\mathrm{NL}$, with significant differences between the treatments. The changes in the internode diameter and internode-diameter-to-internode-length ratio of the fifth internode showed the same patterns (NL > SAM > CAF > PSN), with significant differences between the treatments. The two tested cultivars showed the same patterns.

Table 3. Morphological differences in the fifth internode under different shading treatments.

\begin{tabular}{cccccc}
\hline Cultivar & Fifth Internode & NL & SAM & CAF & PSN \\
\hline \multirow{2}{*}{ HN48 } & Internode length $(\mathrm{cm})$ & $5.66 \pm 0.06 \mathrm{~d}$ & $6.68 \pm 0.12 \mathrm{c}$ & $8.56 \pm 0.09 \mathrm{~b}$ & $11.42 \pm 0.17 \mathrm{a}$ \\
& $\begin{array}{c}\text { Internode diameter }(\mathrm{mm}) \\
\text { Internode diameter/internode } \\
\end{array}$ & $6.65 \pm 0.07 \mathrm{a}$ & $6.17 \pm 0.04 \mathrm{~b}$ & $5.99 \pm 0.09 \mathrm{~b}$ & $4.09 \pm 0.07 \mathrm{c}$ \\
& length $(\%)$ & $11.75 \pm 0.58 \mathrm{a}$ & $9.24 \pm 0.06 \mathrm{~b}$ & $7.02 \pm 0.02 \mathrm{c}$ & $3.58 \pm 0.01 \mathrm{~d}$ \\
\hline HN60 & Internode length (cm) & $3.78 \pm 0.07 \mathrm{~d}$ & $4.26 \pm 0.04 \mathrm{c}$ & $5.56 \pm 0.11 \mathrm{~b}$ & $9.16 \pm 0.20 \mathrm{a}$ \\
& Internode diameter (mm) & $5.95 \pm 0.03 \mathrm{a}$ & $5.74 \pm 0.05 \mathrm{~b}$ & $5.64 \pm 0.09 \mathrm{~b}$ & $3.67 \pm 0.05 \mathrm{c}$ \\
& Internode diameter/internode & $16.08 \pm 0.35 \mathrm{a}$ & $13.81 \pm 0.33 \mathrm{~b}$ & $10.34 \pm 0.18 \mathrm{c}$ & $4.01 \pm 0.02 \mathrm{~d}$ \\
\hline
\end{tabular}

Note: NL: natural light treatment; SAM: shading of the apical meristem; CAF: covering of all internodes with aluminum foil; PSN: whole-plant shading with plastic shading nets. The values in the table are the means \pm standard error $(n=5)$, different letters indicate that the difference between treatments reached significance at the level of $p<0.05$, and the treatments are compared horizontally. 


\subsection{Effects of Shading on the Anatomical Structure of Internodes}

Figures 1 and 2 shows cross and longitudinal sections of the middle of the fifth internodes from two cultivars that were shaded continuously under different conditions after the first pair of true leaves expanded. As shown in Figure 1, with the same magnification, as the degree of shading increases, the thickness from the outer epidermis to the pith decreases, and the cortex gradually becomes more densely packed. By comparing the ratios of the xylem area to the pith area under different shading conditions, we found that shading significantly decreased the proportion of xylem area but increased the pith area. The change in the xylem area under the PSN treatment was the greatest, while the difference in the change in the xylem area between the SAM and CAF treatments was not significant, which, in combination with the results in Table 3, is thought to be the main cause of the decrease in internode diameter. Moreover, as shown in the cross-section images, the diameter of vessels under the PSN treatment was significantly smaller than that under each of the other three treatments. The comparison of longitudinal sections from the fifth internode (Figure 2) shows that as the degree of shading increased, cells in the pith were more longitudinally stretched and arranged in a more orderly fashion and more densely, which, in combination with the results in Table 3, is considered the cause of the increased internode length.

subsectionEffects of Shading on Soybean Internode Fiber Composition

To illustrate the effect of shading on the growth of soybean internodes, we measured the fiber composition of the fifth internode. As shown in Figure 3, different shading treatments significantly affected the lignin, cellulose, and hemicellulose contents of soybean stems, and both cultivars showed the same pattern: NL $>$ SAM $>$ CAF $>$ PSN. In combining Figures 1 and 2, we infer that shading significantly reduces the lignin, cellulose, and hemicellulose contents in soybean stems, leading to a significant decrease in the ratio of the xylem area to the pith area, in turn causing a trend toward a decreasing internode diameter (Table 3).

\subsection{Effects of Shading on Soybean Internode $G A_{3}$ Content and Relative Expression Levels of GA-Related Enzyme Genes}

Table 4 shows the changes in the $\mathrm{GA}_{3}$ content of the fifth internode from HN48 and HN60 soybean plants under different shading conditions. After shading for 1 day, the internode $\mathrm{GA}_{3}$ content of $\mathrm{HN} 48$ showed the pattern CAF $>$ PSN $>$ SAM $>\mathrm{NL}$; after shading for 2 days, the pattern changed to PSN $>$ SAM $>$ CAF $>$ NL. Unlike HN48, after shading for 1 day, the internode $\mathrm{GA}_{3}$ content of $\mathrm{HN} 60$ showed the pattern $\mathrm{SAM}>\mathrm{CAF}>\mathrm{PSN}>$ $\mathrm{NL}$; after shading for 2 days, the pattern changed to SAM $>$ PSN $>$ CAF $>$ NL. However, starting on the third day of shading, the two cultivars showed the same pattern: PSN $>\mathrm{CAF}>\mathrm{SAM}>\mathrm{NL}$. The above results indicate that the light-sensitive parts of the two cultivars responded differently to light, resulting in different times at which the soybean stem $\mathrm{GA}_{3}$ content changed. However, the stem $\mathrm{GA}_{3}$ contents of the two cultivars stabilized after 3 days of shading. 

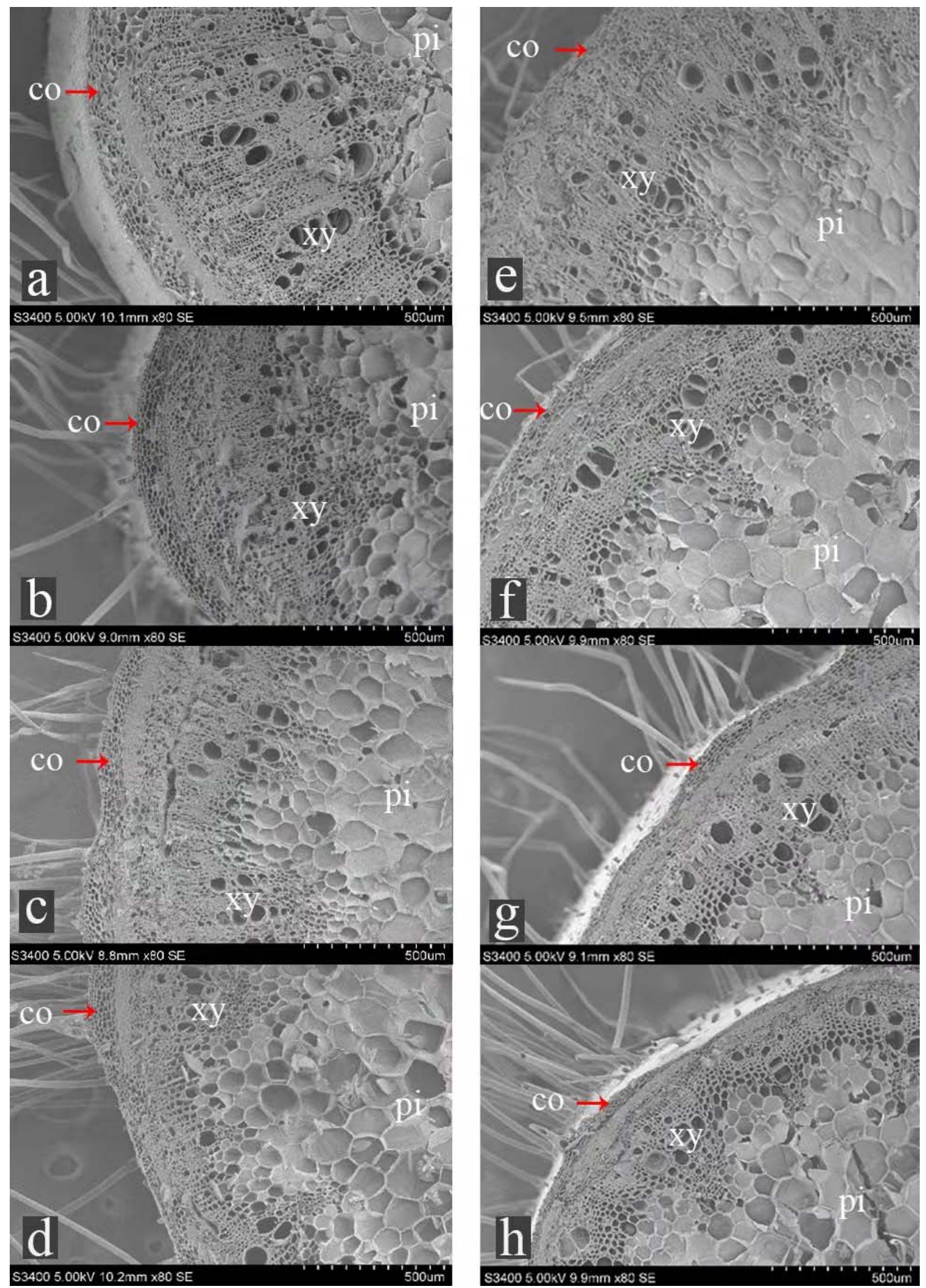

Figure 1. Changes in transverse anatomical structures of soybean stems under shading $(80 \times)$. Note: (a-d) changes in transverse anatomical structures of HN48 soybean stems under shading; (e-h) HN60; $(\mathbf{a}, \mathbf{e})$ natural light; $(\mathbf{b}, \mathbf{f})$ shading of the apical meristem; $(\mathbf{c}, \mathbf{g})$ covering of all internodes with aluminum foil; $(\mathbf{d}, \mathbf{h})$ whole-plant shading with plastic shading nets; co: cortex; xy: xylem; and pi: pith. 



Figure 2. Changes in longitudinal anatomical structures of soybean stems under shading $(80 \times)$. Note: (a-d) changes in transverse anatomical structures of HN48 soybean stems under shading; (e-h) HN60; (a,e) natural light; (b,f) shading of the apical meristem; (c, $\mathbf{g})$ covering of all internodes with aluminum foil; (d,h) whole-plant shading with plastic shading nets; co: cortex; xy: xylem; and pi: pith. 

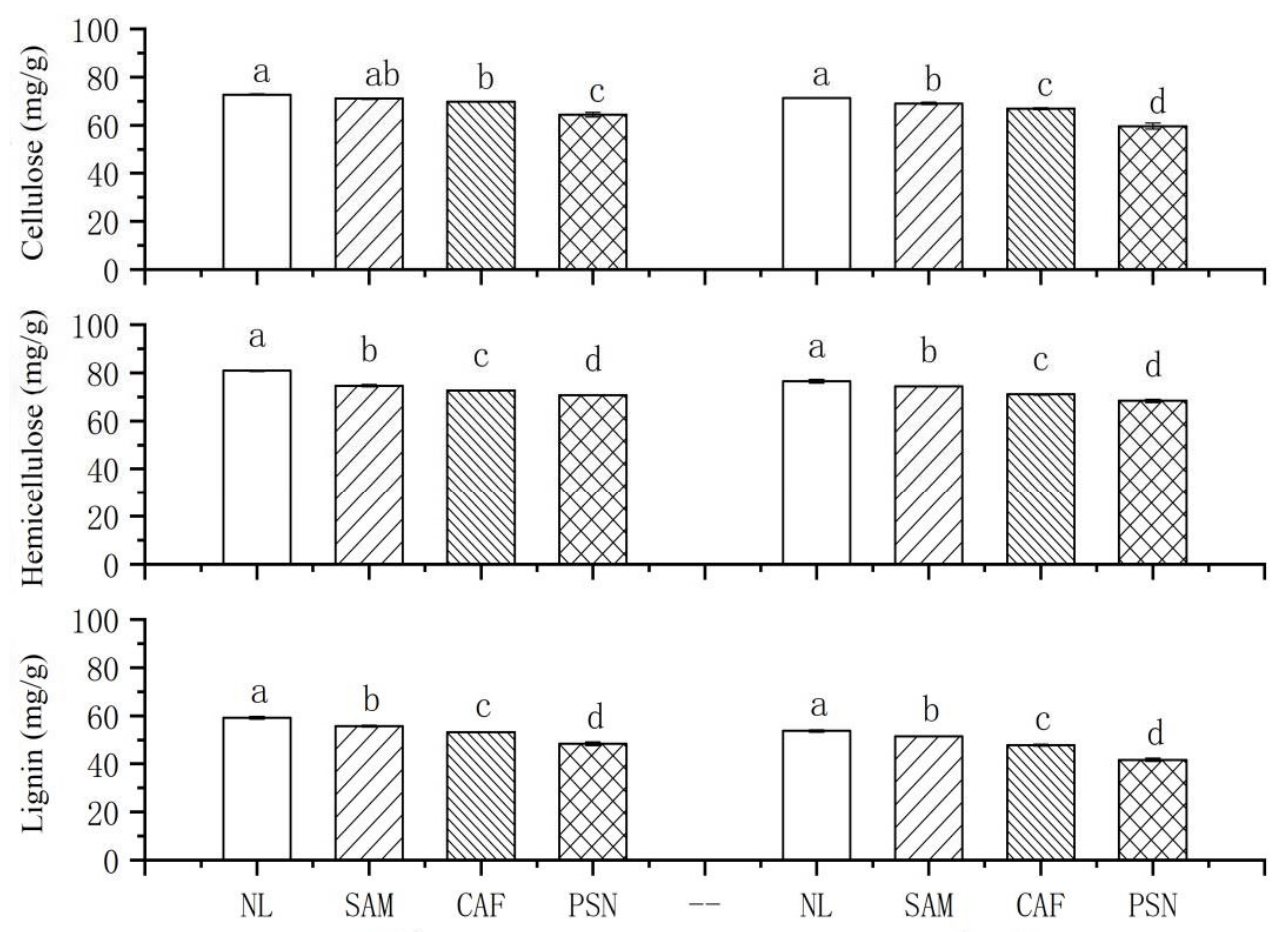

HN48

HN60

Figure 3. Differences in cellulose, hemicellulose, and lignin contents of soybean stems after shading Note: NL: natural light treatment; SAM: shading of the apical meristem; CAF: covering of all internodes with aluminum foil; and PSN: whole-plant shading with plastic shading nets. The different letters indicate that the difference between treatments reached significance at the level of $p<0.05$.

Table 4. Soybean internode $\mathrm{GA}_{3}$ content after shading $(\mu \mathrm{g} / \mathrm{kg})$.

\begin{tabular}{cccccc}
\hline Cultivar & Days/Treatment & NL & SAM & CAF & PSN \\
\hline HN48 & 1 & $21.87 \pm 0.98 \mathrm{c}$ & $24.51 \pm 0.13 \mathrm{c}$ & $58.25 \pm 4.80 \mathrm{a}$ & $36.15 \pm 0.81 \mathrm{~b}$ \\
& 2 & $19.33 \pm 1.08 \mathrm{~d}$ & $41.28 \pm 2.75 \mathrm{~b}$ & $32.14 \pm 1.61 \mathrm{c}$ & $56.61 \pm 1.24 \mathrm{a}$ \\
& 3 & $16.46 \pm 1.26 \mathrm{c}$ & $22.43 \pm 2.48 \mathrm{bc}$ & $28.97 \pm 1.40 \mathrm{~b}$ & $30.08 \pm 2.86 \mathrm{a}$ \\
& 5 & $7.75 \pm 1.52 \mathrm{~d}$ & $18.07 \pm 0.97 \mathrm{c}$ & $23.65 \pm 0.78 \mathrm{~b}$ & $29.34 \pm 0.79 \mathrm{a}$ \\
\hline HN60 & 1 & $11.45 \pm 0.21 \mathrm{c}$ & $19.09 \pm 0.86 \mathrm{a}$ & $17.38 \pm 0.07 \mathrm{~b}$ & $13.08 \pm 0.48 \mathrm{c}$ \\
& 2 & $5.85 \pm 0.13 \mathrm{~d}$ & $9.79 \pm 0.23 \mathrm{a}$ & $7.39 \pm 0.24 \mathrm{c}$ & $8.23 \pm 0.17 \mathrm{~b}$ \\
& 3 & $2.64 \pm 0.06 \mathrm{c}$ & $2.94 \pm 0.03 \mathrm{bc}$ & $3.40 \pm 0.05 \mathrm{~b}$ & $5.39 \pm 0.35 \mathrm{a}$ \\
& 5 & $1.82 \pm 0.07 \mathrm{c}$ & $2.14 \pm 0.15 \mathrm{c}$ & $2.91 \pm 0.04 \mathrm{~b}$ & $3.50 \pm 0.24 \mathrm{a}$ \\
\hline
\end{tabular}

Note: NL: natural light treatment; SAM: shading of the apical meristem; CAF: covering of all internodes with aluminum foil; and PSN: whole-plant shading with plastic shading nets. The values in the table are the means \pm standard error $(n=5)$, different letters indicate that the difference between treatments reached significance at $p<0.05$, and the treatments are compared horizontally.

In addition, to examine the effect of shading on the soybean stem $\mathrm{GA}_{3}$ content, we performed a long-term shading treatment (starting from the expansion of the pair of primary leaves) and a short-term shading treatment (starting after the emergence of the fifth internode) on the soybean plants, and we analyzed the $\mathrm{GA}_{3}$ content of the fifth internode after the internode stopped elongating. Figure $4 a, b$ shows the changes in $\mathrm{GA}_{3}$ content in the fifth internode after it stopped elongating under the above-described shading treatments, indicating that the soybean internode $\mathrm{GA}_{3}$ content under the LS treatment was significantly higher than that under the SS treatment and that the stem $\mathrm{GA}_{3}$ content of the tall cultivar HN48 was significantly higher than that of the dwarf cultivar HN60. 


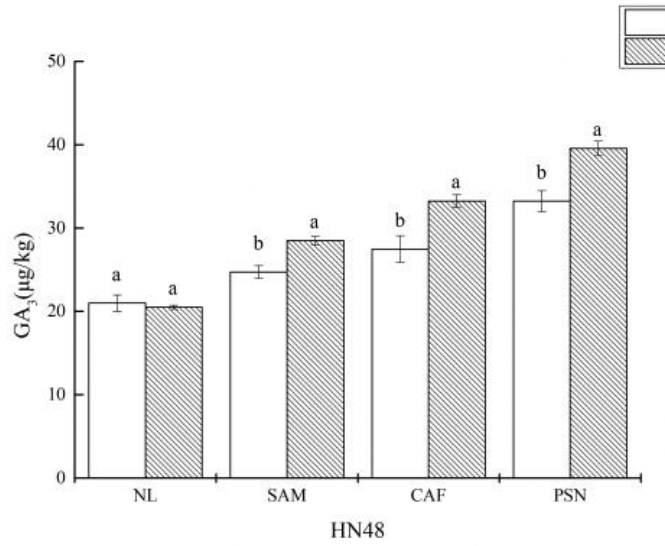

(a)

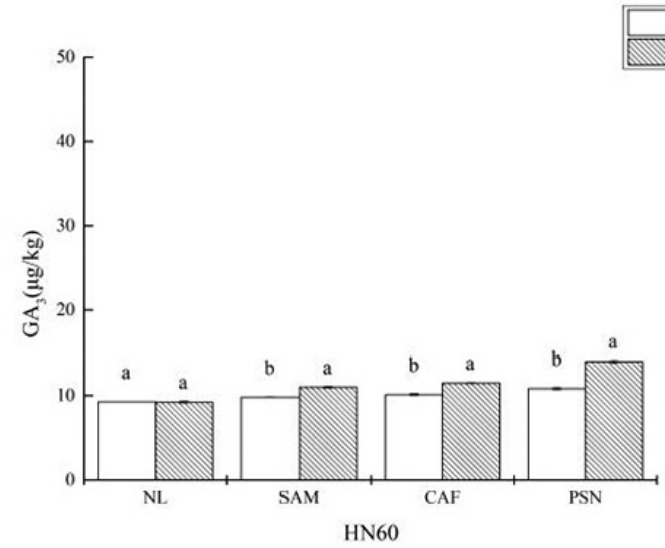

(b)

Figure 4. (a) The soybean stem $\mathrm{GA}_{3}$ contents under different shading conditions in HN48. (b) The soybean stem $\mathrm{GA}_{3}$ contents under different shading conditions in HN60. Note: SS: short-term shading treatment (shading after the fifth internode emerges); LS: long-term shading treatment (shading after true leaves unfold). The different letters indicate that the difference between treatments reached significance at the level of $p<0.05$.

While analyzing the soybean stem $\mathrm{GA}_{3}$ content, we also examined the relative expression levels of the GA3-oxidase, GA20-oxidase, and GA2-oxidase genes in the GA metabolic pathway in soybean stems. As shown in Figure $5 a, b$, the relative expression levels of GmGA3ox6 and GmGA20ox1-D in the two soybean cultivars under shading treatments were higher than those under the NL treatment. As the degree of shading increased, the transcription levels of the two GA synthase genes were upregulated, as was the transcription level of the GA-degrading enzyme gene GmGA2ox4. By combining the results in Table 4 and Figure 5, we found that the relative expression levels of the GA synthase genes GmGA3ox6 and GmGA20ox1-D in soybean stems were essentially consistent with the changes in the stem $\mathrm{GA}_{3}$ content. In addition, the expression levels of the key enzyme genes in the GA metabolic pathway, GmGA3ox6, GmGA20ox1-D, and GmGA2ox4 in HN48, were significantly higher than those in HN60.

Meanwhile, Figure 6a, b shows the relative expression levels of GmGA3ox6, GmGA20ox1$D$, and GmGA2ox4 of different shading methods under short-term and long-term shading treatments, respectively. The results showed that the relative expression levels of GmGA3ox6, GmGA20ox1-D, and GmGA2ox4 in SAM and CAF under long-term shading treatment were significantly higher than that in short-term shading treatment. For PSN, the relative expression levels of GmGA20ox1-D and GmGA2ox4 under long-term shading treatment were significantly higher than that in short-term shading treatment, but there was no significant difference in the relative expression of the GmGA3ox4 gene between them. 




(a)

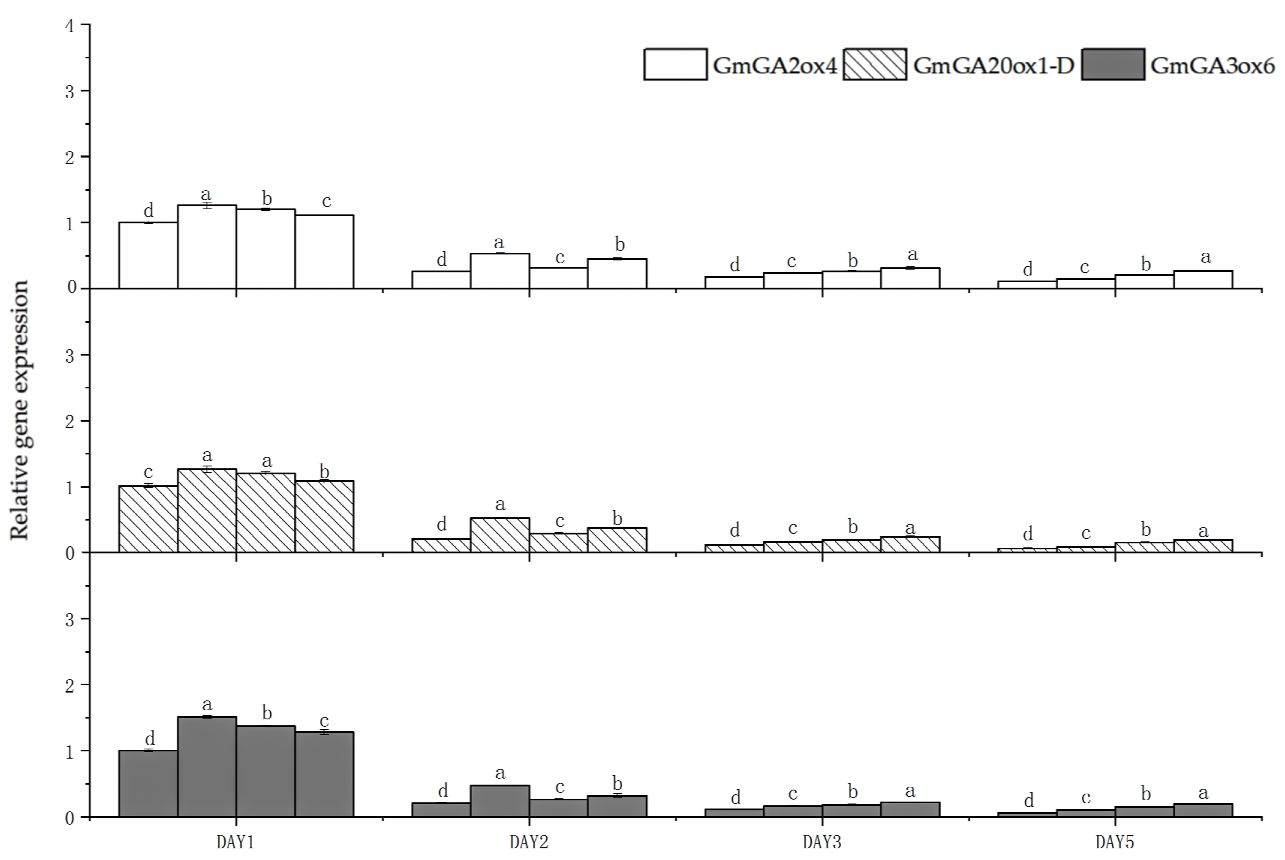

(b)

Figure 5. (a) Expression of GA-responsive genes in soybean stems from HN48. (b) Expression of GA-responsive genes in soybean stems from HN60. Note: NL: natural light treatment; SAM: shading of the apical meristem; CAF: covering of all internodes with aluminum foil; and PSN: whole-plant shading with plastic shading nets. The different letters indicate that the difference between treatments reached significance at the level of $p<0.05$. 




(a)

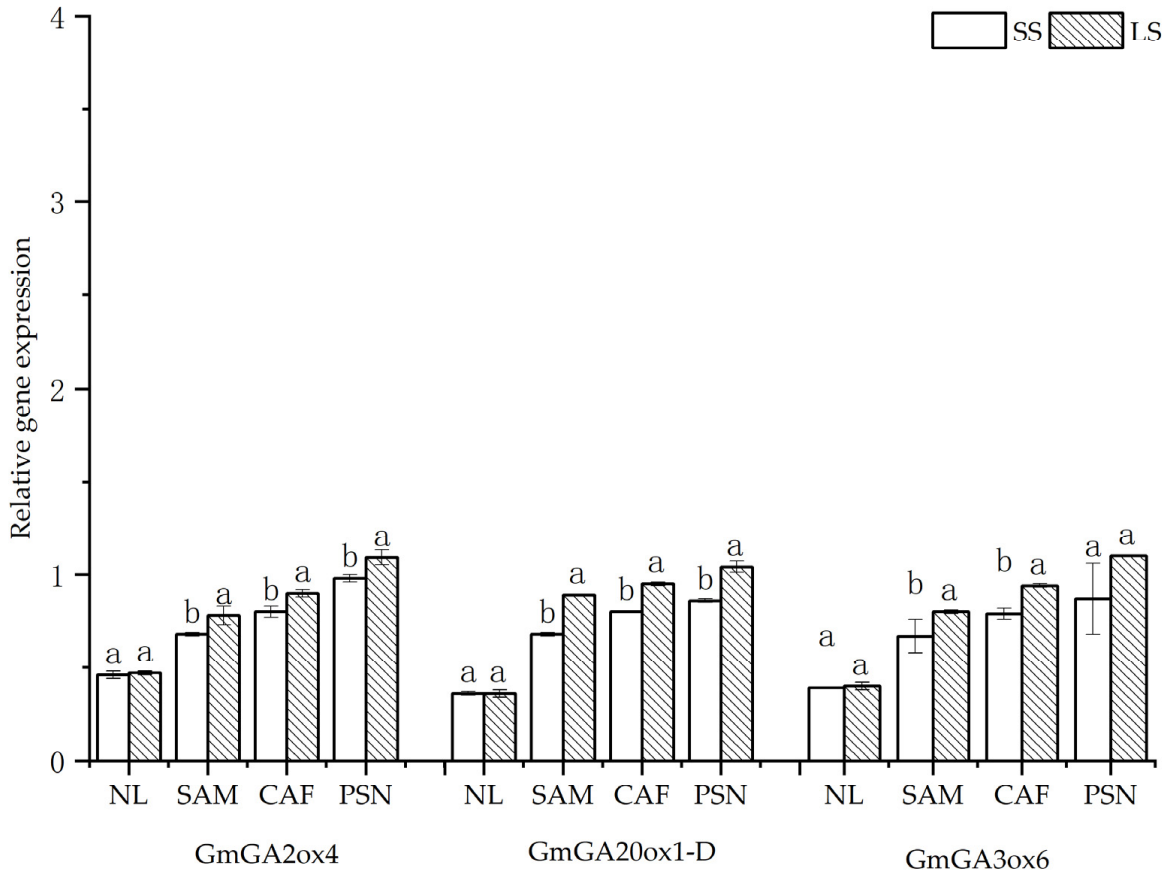

(b)

Figure 6. (a) Expression of GA-responsive genes in soybean stems from HN48. (b) Expression of GA-responsive genes in soybean stems from HN60. Note: NL: natural light treatment; SAM: shading of the apical meristem; CAF: covering of all internodes with aluminum foil; PSN: whole-plant shading with plastic shading nets; SS: short-term shading treatment (shading after the fifth internode emerges); and LS: long-term shading treatment (shading after true leaves unfold). The different letters indicate that the difference between treatments reached significance at the level of $p<0.05$.

\section{Discussion}

Plants under different planting densities show different levels of lodging resistance. Studies have shown that as the density increases, crops such as rice (Oryza sativa L.) [20], wheat (Triticum aestioum L.) [21], corn (Zea mays L.) [22], and rapeseed (Brassica rapa L.) [23] 
exhibit increased plant height and decreased lodging resistance. Xu et al. [24] argued that the photosynthetically active radiation and intensities of red and blue light decrease significantly, but the far-red light intensity decreases only slightly in the light spectrum of the crop canopy, resulting in a significant decrease in the ratio of red light to far-red light (R/FR) in the canopy, forming a shaded environment, which is the main reason for the increase in plant height caused by the change in planting density. In this study, we found that with the increasing of planting density, the lengths of internodes 1-4 were little affected, while the length of the fifth internode changed significantly. This finding is likely the result of the field production conditions: When soybean plants grow to the V3 stage, the crop population gradually forms a closed environment. The growth of the fourth and fifth internodes, as the most vigorously growing internodes, is thus affected. Then, as the plant grows, the higher the planting density is, the greater the decrease in canopy irradiance is, so the internodes above the fifth internode elongate significantly, increasing the risk of plant lodging. Previously, we also found that shading does not change the elongation pattern of soybean internodes [18], and the internodes that have stopped elongating are not affected by the shading environment. Based on actual field production conditions, we conclude that the growth state of the fifth internode from soybean plants is closely related to the lodging of soybean stems.

Plants are often shaded to varying degrees during growth [11], which triggers growth responses that cause the stem and hypocotyl to elongate faster [25,26]. Garrison and Briggs [27] wrapped the internode of sunflowers (Helianthus annuus) with aluminum foil in two ways (in segments or over the entirety of the internode) and found that after the wrapping, the length of the internode increases and that the increase in internode length from wrapping the entire internode is significantly greater than that from wrapping the internode in segments. Garrison concluded that the shading area affects the elongation ability of the stem. In this study, we applied different shading methods (i.e., shading the apical meristem, covering all the internodes with aluminum foil, and performing whole-plant shading with plastic shading nets after the emergence of the fifth internode). We found that in all the shading treatments, the length of the fifth internode increased, indicating that, on the one hand, shading affects soybean stem elongation, and on the other hand, the increase in shading area is positively correlated with stem elongation, consistent with the findings of Garrison [27]. In addition, we found that in all the shading treatments, the diameter-to-length ratio in the fifth internode decreased, with a pattern of PSN $<$ CAF $<$ SAM $<$ NL. Xu et al. [24] proposed that the diameter-to-length ratio of the stem internode is an effective indicator of lodging resistance in plant stems. Therefore, we conclude that shading light-sensitive parts weakens the lodging resistance of soybean stems and that the tall cultivar HN48 is much more affected than the dwarf variety HN60 in this regard.

According to Keuskamp et al. [28], the cell wall modification mechanism is essential to controlling plant stem elongation. Two protein families, expansin and xyloglucan endotransglucosylase/hydrolase, are involved in cell wall modification. The accumulation of polysaccharides in the cell wall and the formation of secondary cell walls under shading conditions accelerate the hindrance of lateral stem growth, while the increase in hydrolase activity causes relaxation of the cell wall, which increases the radial elongation of the stem. This change might also be the reason why the shading of light-sensitive parts of the stem led to the increased internode length but decreased internode diameter observed in this study. Wen et al. [29] found that shading significantly reduced the areas and proportions of phloem and xylem in soybean stems and increased the proportion of pith cells. Šimura et al. [30] also found that shading reduces stem lignification in cotton seedlings, leading to underdeveloped cambium and phloem and increasing the pith diameter. In this study, we found that shading the light-sensitive parts of soybean stems reduces the xylem area of the fifth internode, causes a more densely packed cortex, increases the proportion of the pith cell area, and results in more neatly and densely arranged pith cells that are more longitudinally stretched. Moreover, the determination of the lignin, cellulose, and hemicel- 
lulose contents revealed that shading has an effect on the composition and structure of the stem, likely due to changes in the plant to maximally adapt to the shading environment.

Responses of plant hormones to shading are an active response of soybean plants to tolerate adverse environments. Changes in plant hormones provide a physiological basis for the plant to use assimilation products and alleviate yield reduction to the greatest extent. The main plant hormones include auxins, ethylene, brassinolides, and GAs, and GAs are required to provide signals for the shade avoidance response of phyB [31]. In this study, we found that the $\mathrm{GA}_{3}$ content in the stems of the two soybean cultivars changed at different times. However, the stem $\mathrm{GA}_{3}$ contents of the two cultivars stabilized after 3 days of shading. The similarity between the two is that the internode $\mathrm{GA}_{3}$ content was the highest at the beginning of shading; it then gradually decreased and increased again when the internode stopped elongating. We speculate that this finding might be a result of the changes in the growth state of soybean internodes. In the vigorous growth stage, the stem $\mathrm{GA}_{3}$ content is higher and the light-sensitive tissues are more sensitive to light, while under shading, $\mathrm{GA}_{3}$ synthesis is faster. As the internodes gradually mature, $\mathrm{GA}_{3}$ begins to be preferentially distributed to the vigorously growing internodes, resulting in a gradual decrease in the stem $\mathrm{GA}_{3}$ content. However, as the fifth internode stops elongating, soybean plants enter the flowering period, and the stem $\mathrm{GA}_{3}$ content increases again. Yuan [13] found that the $\mathrm{GA}_{3}$ content in the leaves of Himalayan lily (Cardiocrinum giganteum) under shading peaked during the blooming stage and then decreased. Nishijima et al. [32] also showed that an increase in plant $\mathrm{GA}_{3}$ content is one of the necessary conditions for flowering, also validating the above speculation.

The level of GAs in plants is determined by the relative strengths of two metabolic pathways: GA synthesis and degradation. Studies have shown that three key enzyme genes, GA20ox, GA3ox, and GA2ox, are involved in GA biosynthesis [33]. In this study, we quantitatively analyzed three key GA-related enzyme genes (GA20ox, GA3ox, and $G A 20 x)$ and found that the transcription levels of GA synthase genes ( $G m G A 30 x 6$ and GmGA20ox1-D) were upregulated, while that of the GA-degrading enzyme gene GmGA2ox4 was upregulated. Moreover, we found that with 1 day of shading, the CAF treatment of HN48 resulted in the highest gene expression, while the SAM treatment of HN60 resulted in the highest gene expression; the PSN treatment of the two cultivars showed the largest effect after 3 days of shading. We speculate that there might be two reasons for these findings. First, when a single part of the plant is shaded, the $\mathrm{GA}_{3}$ content of the plant quickly reaches a balanced state, whereas when the whole plant is shaded, it requires the adjustment of different parts of the plant to reach the same stable state of $\mathrm{GA}_{3}$ content. Second, the change in $\mathrm{GA}_{3}$ content is affected by the internode growth status. Soybean plants grow a new internode every 3 days on average, during which the $\mathrm{GA}_{3}$ content changes too quickly to be noticed. These speculations must still be experimentally verified. Furthermore, we compared the relative expression levels of GA-related enzyme genes in soybean stems under the short- and long-term shading treatments and found that the relative expression levels of GA-related enzyme genes were related to the time and area of shading. Yang et al. [34] revealed that under shading, the expression of the GA-synthesis genes GA3ox and GA20ox increases, in turn leading to an increase in GA content, consistent with the conclusion of this study that various shading treatments can induce changes in the expression of GA-related enzyme genes, which in turn leads to an increase in $\mathrm{GA}_{3}$ content.

In addition, we found that the stem $\mathrm{GA}_{3}$ content of the tall cultivar $\mathrm{HN} 48$ was much higher than that of the dwarf cultivar HN60. In combination with the results shown in Table 3, we found that the dwarf cultivar HN60 was more lodging resistant than the tall cultivar $\mathrm{HN} 48$, indicating that the $\mathrm{GA}_{3}$ content of a cultivar can reflect its lodging resistance level to some extent. Liu et al. [35] found that shade-tolerant cultivars maintained a low level of ethylene by decreasing $\mathrm{GA}_{3}$ content to maintain normal stem morphology and prevent lodging. Therefore, we conclude that changes in the content of endogenous plant hormones in soybean plants in shaded environments directly or indirectly affect crop 
morphology, also providing a new direction for the future study of lodging resistance in densely planted or intercropped soybean plants.

\section{Conclusions}

Under dense planting conditions, the fifth internode of soybean plants is the key internode that affects lodging. Under shading, the length of the fifth internode increased, but its diameter decreased. The anatomical structure of the stem changed considerably, manifesting in a decreased xylem area, densely packed cortex, and more longitudinally stretched pith cells arranged in a more orderly fashion and more densely; and the lignin, cellulose, and hemicellulose contents decreased. The relative expression levels of GmGA30x6 and GmGA20ox1-D in soybean stems were upregulated, leading to increased $\mathrm{GA}_{3}$ content in soybean stems, and the relative expression level of GmGA20x4 was also upregulated. Therefore, we conclude that changes in the content of endogenous plant hormones in soybean plants in shaded environments directly or indirectly affect crop morphology, also providing a new direction for the future study of lodging resistance in densely planted or intercropped soybean plants.

Author Contributions: Data curation, K.S.; formal analysis, F.S. and S.G.; funding acquisition, C.Y.; investigation, C.W.; project administration, C.M.; visualization, F.S.; writing—original draft, F.S.; writing - review and editing, R.Z. and C.Y. All authors have read and agreed to the published version of the manuscript.

Funding: Funding provided by the National Key Research and Development Program, Integration, and Demonstration of High-Quality, Light, Simple, and Efficient Cultivation Techniques for Soybean (Grant Number 2020YFD1000903), The Research and Demonstration on Key Techniques of Soybean Crop Rotation and Straw Re-turning for High-Yield in Third Accumulated Temperature Region (Grant Number 2021ZXJ05B03) and Academic Backbone of Northeast Agricultural University (Grant Number 20XG01).

Data Availability Statement: The authors confirm that all data, tables, and figures in this manuscript are original.

Acknowledgments: This work was supported by the College of Agriculture, Northeast Agricultural University, China.

Conflicts of Interest: The authors declare that they have no conflicts of interest.

\section{References}

1. Kashiwagi, T.; Sasaki, H.; Ishimaru, K. Factors Responsible for Decreasing Sturdiness of the Lower Part in Lodging of Rice (Oryza sativa L.). Plant Prod. Sci. 2005, 8, 166-172. [CrossRef]

2. Hiltbrunner, J.; Streit, B.; Liedgens, M. Are seeding densities an opportunity to increase grain yield of winter wheat in a living mulch of white clover? Field Crop. Res. 2007, 102, 163-171. [CrossRef]

3. Valladares, F.; Niinemets, Ü. Shade Tolerance, a Key Plant Feature of Complex Nature and Consequences. Annu. Rev. Ecol. Evol. Syst. 2008, 39, 237-257. [CrossRef]

4. Franklin, K.A.; Whitelam, G.C. Phytochromes and Shade-avoidance Responses in Plants. Ann. Bot. 2005, 96, 169-175. [CrossRef] [PubMed]

5. Gong, W.Z.; Jiang, C.D.; Wu, Y.S.; Chen, H.H.; Liu, W.Y.; Yang, W.Y. Tolerance vs. avoidance: Two strategies of soybean (Glycine max) seedlings in response to shade in intercropping. Photosynthetica 2015, 53, 259-268. [CrossRef]

6. Liu, W.G.; Deng, Y.C.; Hussain, S.; Zou, J.L.; Yuan, J.; Luo, L.; Yang, C.Y.; Yuan, X.Q.; Yang, W.Y. Relationship between cellulose accumulation and lodging resistance in the stem of relay intercropped soybean [Glycine max (L.) Merr.]. Field Crop. Res. 2016, 196, 261-267. [CrossRef]

7. Liu, W.G.; Hussain, S.; Liu, T.; Zou, J.L.; Ren, M.L.; Zhou, T.; Liu, J.; Yang, F.; Yang, W.Y. Shade stress decreases stem strength of soybean through restraining lignin biosynthesis. J. Integr. Agric. 2019, 18, 43-53. [CrossRef]

8. Hussain, S.; Iqbal, N.; Pang, T.; Khan, M.N.; Liu, W.G.; Yang, W.Y. Weak stem under shade reveals the lignin reduction behavior. J. Integr. Agric. 2019, 18, 496-505. [CrossRef]

9. Cheng, B.; Raza, A.; Wang, L.; Xu, M.; Lu, J.; Gao, Y.; Qin, S.; Zhang, Y.; Ahmad, I.; Zhou, T.; et al. Effects of Multiple Planting Densities on Lignin Metabolism and Lodging Resistance of the Strip Intercropped Soybean Stem. Agronomy 2020, 10, 1177. [CrossRef] 
10. Zhang, J.; Smith, D.L.; Liu, W.G.; Chen, X.F.; Yang, W.Y. Effects of shade and drought stress on soybean hormones and yield of main-stem and branch. Afr. J. Biotechnol. 2011, 10, 14392-14398. [CrossRef]

11. Wu, Y.S.; Gong, W.Z.; Yang, W.Y. Shade Inhibits Leaf Size by Controlling Cell Proliferation and Enlargement in Soybean. Sci. Rep. 2017, 7, 9259. [CrossRef] [PubMed]

12. Yang, F.; Fan, Y.F.; Wu, X.L.; Cheng, Y.J.; Liu, Q.L.; Feng, L.Y.; Chen, J.X.; Wang, Z.L.; Wang, X.C.; Yong, T.W.; et al. Auxin-toGibberellin Ratio as a Signal for Light Intensity and Quality in Regulating Soybean Growth and Matter Partitioning. Front. Plant Sci. 2018, 9, 56-71. [CrossRef] [PubMed]

13. Yuan, Y.; Yang, W.Y. Effects of Shading on Endogenous Hormone of Cardiocrinum Giganteum. North. Hortic. 2007, 8, $123-125$.

14. Gawronska, H.; Yang, Y.Y.; Furukawa, K.; Kendrick, R.E.; Takahashi, N.; Kamiya, Y. Effects of Low Irradiance Stress on Gibberellin Levels in Pea Seedlings. Plant Cell Physiol. 1995, 36, 1361-1367. [CrossRef]

15. Suo, H.C.; Ma, Q.B.; Ye, K.X.; Yang, C.Y.; Tang, Y.J.; Hao, J.; Zhang, Z.Y.; Chen, M.L.; Feng, Y.Q.; Nian, H. Overexpression of AtDREB1A causes a severe dwarf phenotype by decreasing endogenous gibberellin levels in soybean [Glycine max (L.) Merr.]. PLoS ONE 2012, 7, e1515. [CrossRef]

16. Hedden, P.; Phillips, A.L. Gibberellin metabolism: New insights revealed by the genes. Trends Plant Sci. 2001, 5, 523-530. [CrossRef]

17. Coles, J.P.; Phillips, A.L.; Croker, S.J.; García-Lepe, R.; Lewis, M.J.; Hedden, P. Modification of gibberellin production and plant development in Arabidopsis by sense and antisense expression of gibberellin 20-oxidase genes. Plant J. 1999, 17, 547-556 [CrossRef]

18. Zhang, R.; Shan, F.X.; Wang, C.; Yan, C.; Dong, S.K.; Xu, Y.; Gong, Z.P.; Ma, C.M. Internode elongation pattern, internode diameter and hormone changes in soybean (Glycine max) under different shading conditions. Crop Pasture Sci. 2020, 71, 679-688. [CrossRef]

19. Sauter, M.; Kende, H. Gibberellin-induced growth and regulation of the cell division cycle in deepwater rice. Planta 1992, 188, 362-368. [CrossRef]

20. Reza, Y.; Morteza, S.; Hamidreza, M.; Dastan, S.; Alireza, N. Effect of Plant Density on Morphologic Characteristics Related to Lodging and Yield Components in Different Rice Varieties (Oriza Sativa L.). J. Agric. Sci. 2011, 4, 31. [CrossRef]

21. Zheng, M.J.; Chen, J.; Shi, Y.H.; Li, Y.X.; Yin, Y.P.; Yang, D.Q.; Luo, Y.L.; Pang, D.W.; Xu, X.; Li, W.Q.; et al. Manipulation of lignin metabolism by plant densities and its relationship with lodging resistance in wheat. Sci. Rep. 2016, 7, 19-26. [CrossRef] [PubMed]

22. Echezona, B.C. Corn-stalk lodging and borer damage as influenced by varying corn densities and planting geometry with soybean (Glycinemax. L. Merrill). Int. Agrophys. 2007, 21, 133-143. [CrossRef]

23. Khan, S.; Anwar, S.; Kuai, J.; Ullah, S.; Fahad, S.; Zhou, G.S. Optimization of Nitrogen Rate and Planting Density for Improving Yield, Nitrogen Use Efficiency, and Lodging Resistance in Oilseed Rape. Front. Plant Sci. 2017, 8, 532. [CrossRef] [PubMed]

24. Xu, Y.; Zhang, R.; Hou, Z.F.; Yan, C.; Xia, X.; Ma, C.M.; Dong, S.K.; Gong, Z.P. Mechanical properties of soybean plants under various plant densities. Crop Pasture Sci. 2020, 71, 249-259. [CrossRef]

25. Tao, Y.; Ferrer, J.L.; Ljung, K.; Pojer, F.; Hong, F.; Long, J.A.; Li, L.; Moreno, J.E.; Bowman, M.E.; Ivans, L.J.; et al. Rapid synthesis of auxin via a new tryptophan-dependent pathway is required for shade avoidance in plants. Cell 2008, 133, 1-176. [CrossRef] [PubMed]

26. Kohnen, M.V.; Schmid-Siegert, E.; Trevisan, M.; Petrolati, L.A.; Sénéchal, F.; Müller-Moulé, P.; Maloof, J.; Xenarios, I.; Fankhauser, C. Neighbor detection induces organ-specific transcriptomes, revealing patterns underlying hypocotyl-specific growth. Plant Cell 2016, 28, 2889-2904. [CrossRef]

27. Garrison, R.; Briggs, W.R. Internodal Growth in Localized Darkness. Bot. Gaz. 1972, 133, 270-276. [CrossRef]

28. Keuskamp, D.H.; Sasidharan, R.; Pierik, R. Physiological regulation and functional significance of shade avoidance responses to neighbors. Plant Signal. Behav. 2010, 5, 655-662. [CrossRef]

29. Wen, B.; Zhang, Y.; Hussain, S.; Wang, S.; Zhang, X.; Yang, J.; Xu, M.; Qin, S.; Yang, W.; Liu, W. Slight shading stress at seedling stage does not reduce lignin biosynthesis or affect lodging resistance of soybean stems. Agronomy 2020, 10, 544. [CrossRef]

30. Šimura, J.; Antoniadi, I.; Široká, J.; Tarkowská, D.; Strnad, M.; Ljung, K.; Novák, O. Plant hormonomics: Multiple phytohormone profiling by targeted metabolomics. Plant Physiol. 2018, 177, 476-489. [CrossRef]

31. Colebrook, E.H.; Thomas, S.G.; Phillips, A.L.; Hedden, P. The role of gibberellin signalling in plant responses to abiotic stress. J. Exp. Biol. 2014, 217, 67-75. [CrossRef] [PubMed]

32. Nishijima, T.; Katsura, N.; Koshioka, M.; Yamazaki, H.; Nakayama, M.; Yamane, H.; Yamaguchi, I.; Yokota, T.; Murofushi, N.; Takahashi, N.; et al. Effects of Gibberellins and Gibberellin-biosynthesis Inhibitors on Stem Elongation and Flowering of Raphanus sativus L. J. Jpn. Soc. Hortic. Sci. 2008, 67, 325-330. [CrossRef]

33. Plackett, A.R.G.; Powers, S.J.; Fernandez-Garcia, N.; Urbanova, T.; Takebayashi, Y.; Seo, M.; Jikumaru, Y.; Benlloch, R.; Nilsson, O.; Ruiz-Rivero, O.; et al. Analysis of the developmental roles of the arabidopsis gibberellin 20-oxidases demonstrates that GA20ox1, -2 , and -3 are the dominant paralogs. Plant Cell 2012, 24, 941-960. [CrossRef] [PubMed]

34. Yang, C.; Li, L. Hormonal regulation in shade avoidance. Front. Plant Sci. 2017, 8, 1527. [CrossRef]

35. Liu, W.G.; Jiang, T.; She, Y.H.; Yang, F.; Yang, W.Y. Preliminary study on physiological response mechanism of soybean (Glycinemax) stem to shade stress at seedling stage. Chin. J. Oil Crop Sci. 2011, 33, 141-146. 